\title{
Vigotski e a perspectiva enunciativa da relação entre linguagem, cognição e mundo socia* ${ }^{*}$
}

\author{
Edwiges Maria Morato**
}

\begin{abstract}
'É um homem falando que encontramos no mundo, um homem falando a outro homem, e a linguagem ensina a própria definição de homem"

(É. Benveniste)
\end{abstract}

\begin{abstract}
RESUMO: A finalidade deste artigo é, a partir da teorização que se projeta na área da Lingüística, discutir alguns aspectos da reflexão vigotskiana sobre a linguagem. Especialmente, interessa-nos refletir acerca das propriedades semiológicas que Vigotski, em seus escritos, estabelece entre linguagem e cognição. Nesse sentido, o presente trabalho inter-relaciona Vigotski com alguns autores com os quais manteria um "ar de família", como Humboldt, Bakhtin e Benveniste, a fim de explorar sua perspectiva enunciativa da relação entre linguagem e cognição.
\end{abstract}

Palavras-chave: Significação, enunciação, cognição, interação, lingüística

Introdução: a relevância do legado vigotskiano para a reflexão lingüística

A variedade de temas que Vigotski abordou parece buscar um sentido unitário que, a despeito das contradições e incongruências teóricas

\footnotetext{
* Texto originalmente publicado nos anais de um ciclo de colóquios promovido pela Faculdade de Educação da Unicamp em torno do "Centenário de nascimento de Piaget, Freinet, Vigotski e Jakobson", organizado por Ana Luíza Smolka (1997). Com bem poucas - mas importantes - alterações, o presente texto representa uma segunda versão do apresentado no referido evento.

** Instituto de Estudos da Linguagem (IEL)/Unicamp. E-mail: edwiges@iel.unicamp.br
} 
que podemos identificar em seu percurso intelectual, faz desse construto um corpo cujas partes não podemos considerar isoladamente. Eis porque a insulação de algumas idéias ou a subordinação de umas em relação às outras, separadas em perspectiva e tempo, impedem uma interpretação mais ou menos comum de sua obra por parte dos estudiosos.

O que é realmente admirável é que Vigotski não encerrou, com sua morte, a enorme vitalidade que se pode encontrar em sua obra. Talvez por isso não se possa dar a uma dinâmica elaboração teórica um sentido estático, o que se faz ao procurar um e apenas um sentido formal para determinado conceito ou categoria. Penso que uma boa estratégia para escapar de tal postura seria perguntarmos a respeito de algumas categorias com as quais ele trabalhou: o que Vigotski teria em mente quando se referia à linguagem? Como diferentes autores influenciaram implícita ou explicitamente o seu pensamento? Qual a importância de suas idéias hoje em dia?

Do ponto de vista das atuais teorias ou vertentes lingüísticas, Vigotski é um autor indefensável por vários motivos. A psicolingüística poderia acusar sua reflexão acerca do desenvolvimento cognitivo de teleológica; os estudos em aquisição de linguagem poderiam apontar como problemática uma questão central em sua obra, relacionada com a emergência de uma função "reguladora" da linguagem, quer seja sobre os processos cognitivos, quer seja sobre as ações próprias e alheias: afinal, poderia ser indagado, como pode uma criança que ainda não objetiva o outro, nem a si própria ou a própria linguagem, engajar-se em processos comunicativos? A neurolingüística poderia explorar suas contradições a respeito da relação entre linguagem e cognição, bem como a ausência de pesquisa empírica suficiente para sustentar inteiramente suas teses sobre ela.

Não obstante, acabamos por manter com Vigotski o que Wittgenstein em Investigações Filosóficas (1975) chama de "semelhanças de família", referindo-se a conceitos cujas aplicações não são regidas por uma essência imutável ou a posições que não seriam inconciliáveis entre si. Analisando os diferentes postos de observação da obra de Vigotski e os diferentes autores que circulam em torno de seu legado teórico, podemos notar essas "semelhanças de família" muitas vezes não reivindicadas ou confessas. Provavelmente é essa a razão de estarmos, os autores deste volume, reunidos em torno da obra de Vigotski: há entre todos um certo "ar de família" que foi elegantemente descrito por Lahud em seu estudo sobre o pensamento jansenista, cujo discurso é contraditório e cuja única 
unidade possível é não uma reação aos jesuítas ou ao jesuitismo, mas a uma visão trágica do mundo que este representa:

\begin{abstract}
Em suma, nem companheiros de uma mesma escola ou comunidade doutrinária, nem camaradas de um mesmo partido no seio da Igreja, os jansenistas parecem, efetivamente, bem mais constituir uma espécie de família espiritual ou, para usarmos uma bela expressão de Lukàcs: um grupo de irmãos perseguindo as mesmas estrelas. (Lahud 1992, p. 181).
\end{abstract}

O "ar de família" que é capaz de ligar Vigotski tanto a Humboldt quanto a Bakhtin ou às teorias enunciativas (ou seja, aquelas que se preocupam com as relações do sujeito com diferentes instâncias de uso da linguagem) torna-se possível quando levamos em conta que todos se recusam a conceber a linguagem como simplesmente signo. Saussure a concebia como um signo. Eles a concebem como "trabalho", como "atividade", como "processo", como "ação" sobre o pensamento e sobre a cultura. Para lembrar o termo grego empregado por Humboldt, como energeia. Para ele, a linguagem é um trabalho do pensamento que ganha forma por sua vez pela atividade constitutiva da linguagem: "A linguagem não é uma obra (ergon), mas uma atividade (energeia)", diz Humboldt, em uma passagem sempre lembrada. Esse "ar de família" é o que no fundo autoriza a compatibilidade que procuro entrever entre algumas das reflexões vigotskianas sobre a linguagem e uma lingüística de tendência enunciativa, e entre suas reflexões sobre as propriedades (semiológicas) da relação linguagem-cognição e um certo modo de interpretar sua tese da "mediação simbólica", segundo a qual não há possibilidades integrais de conteúdos cognitivos fora da linguagem, nem possibilidades integrais de linguagem fora de processos interativos humanos (cf. Morato 1996). Isso, aliás, já se vê claramente em uma afirmação reveladora que se pode ler em um manuscrito seu de 1929, publicado com o título "Psicologia concreta do homem": "a reflexão é uma discussão".

Embora pareça paradoxal, pensar Vigotski hoje não é necessariamente se referir à sua obra. Sobretudo porque ler ou falar de Vigotski passa por uma crítica às representações que fazemos de Vigotski. Pensar Vigotski é pensar os autores que se reclamam vigotskianos. Pensar Vigotski hoje passa pela análise de filiações teóricas não expressamente reivindicadas, como as relativas a Bakhtin (ou melhor, a Jakubinsky), a Humboldt (ou melhor, a Bühler), a Saussure (ou melhor, a Potebnia, representante russo mais próximo do lingüista genebrino). Pensar Vigotski hoje 
em dia é pensar a historicidade radical da relação entre linguagem e cognição como forma de reação à maneira como a tradição ocidental tem pensado o sentido, isto é, em termos de uma não-linguagem, ou de um obstáculo epistemológico para se pensar a linguagem em sua relação com a cognição e com o mundo (como se pudéssemos admitir seriamente uma espécie de anti-biologismo tout court). Esta historicidade o aproxima de um autor moderno, para quem a linguagem, muito antes de servir para comunicar, serve para viver (Benveniste 1966), ou seja, para significar.

Pensar Vigotski, em suma, é interpretar Vigotski. E se essa afirmação for verdadeira, duas posições estariam impossibilitadas de fazê-lo: o ecletismo acadêmico e a exegese, que teriam por ambição chegar ao âmago do pensamento de Vigotski. Ora, este, por definição, como nos lembra Meschonnic (1995), não pode compreender-se a si mesmo.

Sendo assim, escolho o domínio da interpretação como a melhor aproximação a ser feita com a obra inacabada de um autor prolífero, contraditório e apaixonado, morto ainda jovem num tempo caracterizado por um verdadeiro mosaico de inteligibilidades. Sendo assim, assinalo que todas as minhas reflexões sobre Vigotski têm a lingüística como posto de observação e suas idéias a respeito da linguagem e seu funcionamento como ancoradouro para possíveis ilações a respeito do interesse despertado por sua obra em áreas como a psicolingüística ou a neurolingüística. Ambas possuem, cada uma a sua maneira, um domínio empírico que não deixa de ser um tipo de apreensão da linguagem e da cognição extremamente interessante quando em diálogo com as questões levantadas por Vigotski há muito tempo.

Dito isso, dois movimentos teóricos realizados direta ou indiretamente por Vigotski vão me interessar neste texto: o primeiro diz respeito à perspectiva enunciativa que ele deixa apenas entrever na relação entre linguagem, cognição e mundo social; o segundo diz respeito ao papel "regulador" conferido à linguagem nessa relação.

\section{Visão geral das relações entre linguagem e cognição nas reflexões de Vigotski}

Sabe-se que, como conseqüência do dualismo ontológico, o fenômeno mental (cognitivo) tem sido primeiramente vinculado ao biológico, 
e concebido praticamente à margem da linguagem. Se quisermos resumir a história da tradição filosófica acerca da mente, observaremos, como o fez Dascal (1983), que a relação entre linguagem e cognição, assim, ou é externa, em termos de que ambas são tomadas como elementos logicamente independentes e heterogêneos entre si, ou interna, por uma relação de instrumentalidade (na medida em que a linguagem desempenharia, nesse ponto de vista, uma função meramente instrumental, psico-técnica, frente à cognição). No entanto, tanto em uma abordagem como em outra, a linguagem nada mais é que mera representação mental: ou as operações mentais representam ou produzem representações, atuando a partir de uma instância superior e anterior às experiências significativas do sujeito com a "coisalidade", com as referências do mundo sócio-cultural. Esta instância, da ordem do biológico (mental), assegura - ainda que a partir do concurso da linguagem - 0 acesso ao mundo que se nos apresenta, o "real". Assim, a atividade do conhecimento darse-ia em termos puramente intra-subjetivos, isto é, na mente das pessoas, que não teriam como representar, apreender, categorizar ou localizar as coisas do mundo físico a não ser pelo uso do instrumento simbólico (verbal) pré-concebido.

A relação interna (de constitutividade) que Vigotski aponta entre linguagem e cognição torna possível uma articulação do tipo epistemológico entre seu construto teórico e uma Lingüística de orientação enunciativa, cujos interesses se pautam pela análise dos processos de significação e dos vários movimentos de sentido em jogo nas diversas práticas discursivas. Reside aqui, provavelmente, a maior contribuição dos trabalhos de Vigotski para certas áreas da lingüística, que ganham força se orientadas discursivamente: como ele próprio diz (1987), a respeito do percurso simbólico que coloca em relação as palavras e as coisas: "só a linguagem põe essa relação a claro".

É a significação, nessa abordagem, o fenômeno lingüístico por excelência: o "feixe de sentidos", como diz Pêcheux (1990), organizado (e reorganizado) por estratégias de gestão social, graças ao papel mediador tributário da linguagem. Com isso, reconhece-se que a língua não é simplesmente um intermediário entre nosso pensamento e o mundo. Há vários fatores que mobilizam esta relação, além dos concernentes ao sistema lingüístico propriamente dito (a língua): as propriedades biológicas e psíquicas de que somos dotados, a qualidade das interações humanas, o valor intersubjetivo da linguagem, as contingências materiais da vida em sociedade, os diferentes universos discursivos ou sistemas de refe- 
rência antropo-cultural - para usar uma expressão de Franchi (1977) -, através dos quais agimos e orientamos nossas ações no mundo, as normas pragmáticas que presidem a utilização da linguagem, a polissemia existente entre língua e (inter)discurso. Dito de outra forma, creio que Vigotski estaria uma vez mais em consonância com Humboldt: ainda que o mundo não seja produto original da linguagem (cf. Humboldt, 1972), ele é - digamos - de sua responsabilidade.

Se o mundo se nos apresenta simbolicamente, parece intuir Vigotski, não há possibilidades integrais de conteúdos cognitivos ou domínios do pensamento fora da linguagem, nem possibilidades integrais de linguagem fora dos processos interativos humanos. Este postulado parece ser concebido sob inspiração humboldtiana e já anuncia o papel da linguagem frente ao nosso processo de percepção ou interpretação do real. Não é à toa que, ao descrever o processo de desenvolvimento lingüísticocognitivo da criança, a linguagem surge, para ele, num primeiro momento, como construção da atividade "consciente", e depois (num sentido reflexivo), como seu instrumento - o que coloca Vigotski entre os que entendem que a relação entre linguagem e cognição (e não apenas "pensamento") passa pela noção de significação (e não propriamente pela noção de comunicação ou pela de representação). Assim, a atividade cognitiva, derivada da mediação simbólica, só pode ser compreendida se levarmos alguns postulados de Vigotski às últimas conseqüências, a partir da significação, tal como ela é definida por um outro autor também próximo da reflexão humboldtiana: "uma prática quase-estruturante e social" (Franchi 1986, p. 25).

Se as funções cognitivas também estão na dependência dos diversos processos em jogo na significação, elas não são comportamentos previsíveis ou apriorísticos. Se dependem da significação, são também atos de linguagem.

Se os processos de significação são contextualizados historicamente, parece entender Vigotski, sua sedimentação e sistematicidade pressupõem mudança e autonomia apenas relativas do fenômeno lingüístico ou do cognitivo. Assim sendo, a função reguladora, que emergeria no processo de aquisição da linguagem pela criança, inscreve-se no contexto de imprescindíveis restrições de nossas operações (simbólicas) em torno do mundo social e da própria linguagem. Como bem nota Franchi (1986, p. 30), "o homem estende sua ação pela ação simbólica da linguagem. Mas não há nenhuma razão para supô-la ilimitada”. 
Mas se a linguagem estrutura a realidade, esta realidade é estruturada apenas porque a linguagem assim o estabeleceu? Não, naturalmente. A linguagem apenas predica a realidade, e este é justamente 0 "esplendor de se ter uma linguagem", para lembrarmos Clarice Lispector, afeita às questões metalingüísticas do conhecimento do mundo. Mas ela mesma vai nos lembrar que temos muito mais à medida em que não conseguimos designar. Ou seja, podemos dizer da linguagem que ela é uma ação humana (ela predica, interpreta, representa, influencia, modifica, configura, contingencia, transforma) na mesma proporção em que podemos dizer da ação humana que ela atua também sobre a linguagem: "A linguagem não é parcialmente estruturante porque é parcialmente estruturada, mas é parcialmente estruturante e parcialmente estruturada" (cf. Possenti 1988, p. 72, ênfase minha).

Aqui aparece uma contribuição importante de Vigotski para a sustentação de uma alternativa epistemológica à visão referencial da linguagem, à visão representacionalista. Lendo sobretudo os últimos escritos de Vigotski, somos levados a crer que, para ele, à maneira de Humboldt, se a linguagem tem alguma capacidade de refletir algo, não é nem a si mesma e nem o mundo propriamente, mas as condições de produção e interpretação do sentido. Eis aqui uma abordagem pragmático-enunciativa da relação linguagem-realidade, problema filosófico tradicionalmente tratado pelo viés de uma noção representacionalista da linguagem.

O que Vigotski traz com uma força intempestiva para a pesquisa atual é a idéia de continuidade (não apenas funcional ou estrutural, mas sígnica) entre cognição e linguagem, entre linguagem e cultura, entre cultura e arte, entre arte e política. Essa espécie de continuidade, todavia, é solidária a um movimento descontínuo típico do domínio empírico que lhe dá continente e sustentação. Trata-se, pois, de uma descontinuidade advinda da natureza dinâmica, interativa e fluida da intersecção de vários movimentos de sentido e de diferentes objetos simbólicos (linguagem, sujeito, cognição, história), responsável pela relação de interpretância que o homem mantém com as referências do mundo social, ou com a história. Trata-se, enfim, de uma "continuidade descontínua", que prevê um mundo de relações entre elementos cujas semiologias são distintas, cujas realidades são particulares, ainda que não pertençam a mundos não compossíveis.

Dito de outra forma, a contribuição essencial do pensamento vygotskiano à reflexão lingüística é sobretudo relativa à questão do sentido, essa "fascinante cabeça de Medusa" na expressão feliz de 
Benveniste (1966) - ainda que Vigotski empregue o termo significado no lugar de sentido, provavelmente em função de um tipo de legado saussureano.

É fundamentalmente a questão da significação (o sentido da linguagem) o que está em jogo no debate entre a ciência da linguagem e o cognitivismo, para o qual a linguagem nada mais é que comunicação ou o locus de (produção de) representação. Assim como Vico e Humboldt - dois pensadores da linguagem separados entre si por quase um século - Vigotski situa a linguagem no centro da relação entre corpo e mente, considerando que uma res linguistica é a mediadora entre a res extensa e a res cogitans. Entretanto, foge aos três, é preciso ressaltar, a maneira pela qual a linguagem é posta ou especificada nessa relação. Para Vico (1978), à maneira de Peirce, a linguagem e o lingüístico perdem-se num imenso mundo de imagens e signos. Dito de outra forma, a linguagem perde sua especificidade num mundo semiótico. Um século mais tarde, Humboldt (1972) reconhece ao mesmo tempo a estrutura e a atividade da linguagem, essa res linguística que ultrapassa a imagem e o dualismo ontológico cartesiano. Assim, é Humboldt quem introduz o mundo ou o domínio da linguagem - não da semiose - no pensamento humano: "Historicamente, nós não encontramos um homem no mundo a não ser falando".

É o sentido, e mais especificamente o sentido lingüístico que cria, a partir do interesse suscitado pelos trabalhos de Vigotski, uma espécie de revival dos estudos lingüísticos em torno da cognição humana'. E esta me parece ser a filiação mais contundente de Vigotski à reflexão de Humboldt: uma perspectiva enunciativa da relação entre linguagem e cognição, ancorada na idéia de significação (ou de sentido da linguagem, na expressão de Humboldt 1824, Sprachsinn).

Para Humboldt, é importante lembrar, a significação resulta de várias sínteses que a caracterizam: a poeticidade (voltada para o valor criativo da linguagem e para a atividade subjetiva que forma um objeto no pensamento), a reflexividade (voltada para capacidade específica da linguagem de voltar-se sobre si mesma e para outros sistemas de signos não-verbais), a alteridade (voltada para a presença do outro), a reciprocidade (voltada para o diálogo). Assim, mais do que para comunicar, a linguagem serviria para significar.

O vetor da lingüística humboldtiana é, pois, esse conjunto de propriedades do sentido da linguagem que impõe uma natureza enunciativa 
à relação entre linguagem e cognição. Para Vigotski (1987), vale notar, a significação é o que plasma linguagem e pensamento. Em suas palavras (1987, p. 282):

O pensamento não é somente mediado externamente pelos signos. Ele é mediado internamente pelos sentidos (...) A comunicação da consciência pode ser realizada somente indiretamente, através de um caminho mediado (ênfase minha).

É preciso considerar que quando Vigotski relaciona pensamento e linguagem ele está se referindo basicamente ao pensamento verbal, não a um locus onde a linguagem (e suas categorias lingüísticoontológicas) tem lugar, mas a uma forma de pensamento mediado e impregnado de linguagem, cuja unidade é o sentido da palavra (word meaning - Sprachsinn), que garante a relação entre linguagem e pensamento. Isso implica, entre outras coisas, que tal relação não é direta, unívoca e transparente. Em suma, a transição de um para outro campo passa pela significação, este "princípio regulatório amplamente difundido no comportamento humano", segundo Vigotski (1984, p. 85).

Tomemos, apenas como um exercício de contextualização de algumas reflexões de Vigotski no quadro de modernas teorias enunciativas, uma passagem de Benveniste, com a qual o primeiro certamente concordaria, não fosse seu esforço de apagar, no interior mesmo do funcionalismo, a força do projeto saussureano que acaba por excluir da significação lingüística o sujeito, suas atividades enquanto falante, e a história:

Por que o indivíduo e a sociedade, juntos e por igual necessidade, se fundam na língua? Porque a linguagem representa a mais alta forma de uma faculdade que é inerente à condição humana, a faculdade de simbolizar. Entendamos por aí, muito amplamente, a faculdade de representar o real por um "signo" e de compreender o "signo" como representante do real, de estabelecer, pois, uma relação de "significação" entre algo e algo diferente (...) A transformação simbólica dos elementos da realidade ou da experiência em conceitos é o processo pelo qual se cumpre o poder racionalizante do espírito. O pensamento não é um simples reflexo do mundo; classifica a realidade e nessa função organizadora está tão estreitamente associado à linguagem que 
podemos ser tentados a identificar pensamento e linguagem sob esse aspecto (1966, pp. 27-30, ênfase minha).

\section{A concepção de linguagem como atividade (quase) estruturante}

Se não dissolve os mistérios da significação, e isso não podemos exigir de qualquer autor, Vigotski ao menos nos obriga a levar em conta 0 falso truísmo que aproxima os dois termos, linguagem e cognição.

No cognitivismo não há mediação entre o organismo (a criança, a ação) e o objeto (a linguagem). Há acesso direto. Para Vigotski, um autor que está longe de assumir um anti-biologismo tout court, cabe à linguagem, por suas propriedades formais e discursivas, esse papel duplamente mediador que põe em relação o homem e sua história, a cognição e seu exterior discursivo. Os dados analisados no campo da Aquisição de Linguagem são fundamentais para dar qualidade à descrição do que acontece com a cognição infantil quando de posse da linguagem, de posse dessa "atividade significante por excelência", segundo um postulado típico das correntes enunciativas. Uma vez de posse da linguagem, parece que muda radicalmente as relações da criança com o mundo, com a cognição, com a própria linguagem.

Lembrando que inicialmente a restrição do sentido é condição para a aquisição da linguagem (cf. De Lemos, 1990), as regularidades da práxis histórica encontram nas instâncias enunciativas o tensiômetro crucial das relações humanas: sistematicidade versus indeterminação. Por isso, a função reguladora exercida pela linguagem na descrição vigotskiana da ontogênese, em uma abordagem enunciativamente orientada, só pode ser fluida. As atividades humanas que demandam ações reguladoras lingüísticas e cognitivas - refeitas a cada instância discursiva - só podem ser apreendidas numa região de indeterminação e fluidez que confere à sistemacidade do lingüístico (a língua) e do cognitivo (as operações mentais) um equilíbrio apenas provisório e contingente, porque histórico.

A função organizadora da linguagem emerge, segundo Vigotski, na relação entre a fala e a ação, no momento em que as duas se "deslocam":

Uma vez que as crianças aprendem a usar efetivamente a função planejadora de sua linguagem, o seu campo psicológico muda radicalmente. Uma visão do futuro é, agora, parte integrante de suas 
abordagens ao ambiente imediato (...) Assim, com a ajuda da fala, as crianças adquirem a capacidade de ser tanto sujeito como objeto de seu próprio comportamento. (1984, pp. 29-31)

Para Vigotski, o caminho da criança até o objeto (e vice-versa), e a fala que acompanha a ação ou os apelos verbais diretos aos objetos do mundo, "passam através de outras pessoas". Este trajeto do desenvolvimento da criança é, segundo ele, "o produto de um processo de desenvolvimento profundamente enraizado nas ligações entre história individual e história social" (op. cit., p. 33). Eis aí claramente o valor intersubjetivo e dialógico da linguagem, capaz de "enformar" discursivamente o modo de funcionamento da cognição humana.

A meu ver, a ação reguladora da linguagem estudada por Vigotski no processo de internalização e na análise do funcionamento cognitivo é uma espécie de explicitação da atividade estruturante da linguagem tal como a concebem Franchi (1977) e Lahud (1979), também sob inspiração humboldtiana. Vale notar que Humboldt opõe-se a uma concepção de linguagem que a limita a uma função instrumental na comunicação; para ele, a linguagem não é apenas um veículo externo responsável pelo intercâmbio social, mas "fator indispensável ao desenvolvimento do poder intelectual do homem e para que tenha acesso a uma visão do mundo" (1972).

Como bem assinala Franchi (1977):

... a função primordial da linguagem em Humboldt é, pois, no sentido justo que traçamos, não propriamente a de transmitir aos outros nossas experiências, mas a de "constituí-las". A expressão que corre por toda a obra de Humboldt é "Bildung": por meio da linguagem o homem "dá forma" (bildet) ao mesmo tempo a si mesmo e ao mundo, ou melhor, torna-se consciente de si mesmo, projetando um mundo no exterior.

A propósito dessa questão, diz Franchi (1977):

(...) esse aspecto fundamental da linguagem a torna um instrumento dúctil e eficaz de contínua retificação de todo o anteriormente organizado, remanejando o que se poderia supor imanente, fixo, definitivo. Por outro lado, a atividade lingüística supõe ela mesma esse retorno sobre si mesma (...) de modo a estabelecer uma relação entre os esquemas de ação verbal seletiva e consciente, na 
medida em que reflete sobre o processo mesmo de organização e estruturação verbal; justamente em virtude dessa função, operando sobre signos que se tornam como objetos dessa reflexão, o homem ultrapassa os limites do observável e do perceptível.

Lahud (1979), por sua vez, nos dá uma idéia mais exata do papel da linguagem como a possibilidade de inserção do homem no mundo como um "animal semiótico". Quando não relacionado a um sistema formal, o termo "estruturante" deve ser compreendido:

num sentido bem largo (deveríamos, na verdade dizer pré ou quase-estruturante). Assim, quando falarmos, a título de abreviação, da linguagem natural como "estruturante", cumpre não confundir o resultado dessa atividade com "estruturas" no sentido preciso da palavra, que só as linguagens formais são capazes de produzir (p. 30).

São dois os movimentos teóricos pretendidos por Vigotski para apontar a natureza enunciativa da relação entre linguagem e mundo social. $O$ primeiro pode ser apreendido pela descrição do processo de internalização, em que o outro, e o discurso do outro, orientam as ações da criança, mediando discursivamente a referência (o percurso inter-cognitivo). Internalizando a linguagem do outro, preservando em termos intra-cognitivos seu papel mediador, significativo e organizador, ao qual submete suas próprias ações, a criança passa da condição de interpretada para intérprete de estados de coisas do/no mundo; da dependência da forma dialogal para, a partir da diferenciação dos papéis enunciativos, uma certa "autonomia discursiva"; de uma espécie de consciência dialógica para uma consciência monológica (que, no desenvolvimento lingüístico-cognitivo, resultará na dialogia interna característica do discurso interior, cf. Bakhtin, 1981); da dependência do extra-textual para um progressivo apagamento da necessidade do contexto como indispensável fonte interpretativa - processos estes de objetivação da linguagem, que têm sido tratados por De Lemos e colaboradores em estudos realizados no campo da aquisição de linguagem.

Ainda que servindo-se de categorias que encontrariam melhor abrigo na psicologia ou na pedagogia, todo o movimento teórico realizado por Vigotski em relação à atividade estruturante da linguagem caminha no sentido de explicitar as funções que a linguagem tem (intelectiva, comunicativa, referencial, reguladora) para finalmente compreender o funcionamento que ela é. 
O que tanto o estruturalismo quanto o funcionalismo (e sua combinação mais prolífera, o Círculo Lingüístico de Praga) tinham em comum exerceu uma enorme influência sobre Vigotski: a multifuncionalidade da linguagem, ou seja, a idéia de que a sua variedade funcional obedece a objetivos e condições de diversas situações e ações lingüísticas, ainda que não se possa falar aqui em alguma função dominante ou preponderante. É exatamente desse espírito que Vigotski retira a idéia de pôr em pé de igualdade a função comunicativa e a reguladora, mostrando - tal como o faz Benveniste (1966) muitos anos depois (e com outros interesses) - duas faces do sentido, que se complementam mas não são uma mesma coisa: a comunicação e a significação. ${ }^{2}$ Desse movimento deriva mais uma aproximação que podemos estabelecer entre suas reflexões e as teorias enunciativas.

Redimensionada no contexto de uma perspectiva enunciativa, a ação reguladora da linguagem é condicionada precisamente por uma fluidez que é marcada tanto pela objetalidade do material lingüístico quanto pela indeterminação do sentido deste objeto. Regulação com fluidez, ao que parece, só não permanece como um paradoxo numa perspectiva enunciativa.

Contudo, Vigotski parece aproximar-se e afastar-se seguidamente dos que tiveram alguma influência sobre suas reflexões a respeito da linguagem. Se de Humboldt permanece a consideração de que a linguagem influencia o pensamento e a experiência sócio-cognitiva das pessoas, especialmente em "Thought and Word" (1987), Vigotski vai além, na medida em que, para ele, a linguagem não apenas organiza ou estrutura as experiências, como é organizada ou estruturada por estas.

Ao afirmar que o sentido das palavras (word meaning) é praticamente a origem da ação reguladora da linguagem sobre as ações simbólicas humanas, Vigotski sugere que todo pensamento verbalizado é (auto) regulador. Não se trata de algo puramente metacognitivo: a organização interna da linguagem é fundamentalmente estruturada pelas regularidades enunciativo-discursivas constitutivas das interações humanas.

A noção humboldtiana de signo como a unidade semiótica, bem como a da forma interna da linguagem (Innere Sprachform), presentes de forma a um só tempo sutil e decisiva na reflexão vygotskiana, dão a indicação de que a palavra (ou antes, as memórias discursivas que ela veicula e atesta) torna-se a ponte viva que vincula linguagem e cognição, linguagem e mundo, de maneira necessariamente indireta. O objetivo de Vigotski não pode ir além de apenas indicar que este é um processo mediado. 
Ao dizer que a unidade dessa relação, o pensamento verbal (verbal thinking), guarda a relação entre a interioridade e a exterioridade, constituindo-se uma atividade cognitiva (lingüístico-cognitiva), ele estabelece, à maneira de Bakhtin, uma fronteira dialética de "duas esferas da realidade". ${ }^{3}$

Ao afirmar que a regulação "lingüístico-cognitiva" desenvolve-se num continuum estruturado-estruturante, Vigostki a concebe em termos de uma práxis lingüística sem a qual não há significação. E é por tratar-se de um "contínuo descontínuo" que uma regulação que é ao mesmo tempo fluidez faz irromper o introuvable, o páthos, a ilusão de "controle" do sentido do dizer próprio e alheio, a necessidade do outro e da instância discursiva na construção do sentido do que nós mesmos estamos a dizer ou mostrar.

\section{Comentários finais}

É forte a impressão de que quando uma peça discursiva é extraída de seu contexto, não há salvação possível: o domínio da interpretação é sempre um risco a ser assumido.

Caso Vigotski fosse um psicolingüista de nosso tempo, certamente poderia sofisticar a sua análise e descobrir processos enunciativos distintos dos semânticos, ou descrever melhor a estrutura semântica e as diferenças entre linguagem interna e linguagem externa, além de analisar melhor o momento em que, pela fala egocêntrica - tal como ele a concebe - se articula e se constrói o discurso interior, mental, sob o exterior, social. Contudo, o que Vigotski realmente faz é servir-se de processos hermenêuticos complementares, sobretudo para fazer a mediação entre sua construção teórica e as práticas pedagógicas e clínicas, cuja premência (de ordem prática) procurava atender no contexto social da então União Soviética.

No entanto, ao colocar a interlocução (e, portanto, a enunciação), dentre as outras interações humanas, como representativa da relação entre linguagem e pensamento, e entre linguagem e mundo, Vigotski marcou - como nenhum outro psicólogo - o papel do dialogismo como o elemento constitutivo por excelência dos processos cognitivos e o da interação como fundadora de todo gesto interpretativo humano ("toda ação humana procede de interação", diria um autor russo, Bakhtin, em quem certamente reconhecemos um "ar de família" capaz de vinculá-lo a Vigotski). Em suma, em se tratando da relação entre linguagem, cognição e sociedade, 
Vigotski parece ao longo de sua reflexão estar o tempo todo lembrando Foucault quando este afirma, a respeito da relação entre as palavras e as coisas: "aqui há linguagem".

\section{Notas}

1. É importante que se diga que a continuidade entre significação e linguagem faz com que seja interessante, ao menos para a Lingüística, uma diferenciação na análise do sentido e da significação (entre outras razões, porque é eficaz para o estudo da metalinguagem, da intersubjetividade e do aspecto histórico das instanciações discursivas). Admitamos, por conseguinte, em consonância com as teorias enunciativas (cf. Normand, 1990), que sentido seja a resposta para a pergunta: "O que aquilo (uma palavra, um enunciado, uma enunciação, um signo não verbal) quer dizer?" Já a significação tentaria responder a uma outra questão: "Por quais meios ou processos um enunciado é produzido como tendo sentido?" As duas noções, assim, têm uma relação de reciprocidade.

2. A comunicação nos indica que o sujeito "tem algo a dizer", ou mostrar; a significação nos indica que o sujeito mostra explícita ou implicitamente a maneira pela qual ele corre o risco de interpretar e ser interpretado, de representar ou dar "representabilidade" às coisas do mundo.

3. "A atividade mental tende desde a origem para uma expressão externa plenamente realizada (...) Uma vez materializada, a expressão exerce um efeito reversivo sobre a atividade mental: ela põem-se então a estruturar a vida interior, a dar-Ihe uma expressão ainda mais definida e mais estável. Essa ação reversiva da expressão bem formada sobre a atividade mental tem uma importância enorme, que deve ser sempre considerada. Pode-se dizer que não é tanto a expressão que se adapta ao nosso mundo interior, mas o nosso mundo interior que se adapta às possibilidades de nossa expressão, aos seus caminhos e orientações possíveis" (1981, p. 118, ênfase minha).

Encaminhado para publicação em maio de 2000

\section{Vigotski and the enunciative perspective of the relation between language, cognition and social world.}

ABSTRACT: The aim of this article is to discuss some aspects of vygotskian elaborations about language in the linguistic field. In this sense, we analyze the semiotic proprieties of the relation between language and cognition, proposed by Vygotsky in his works. From 
our point of view, as like as Humboldt, Bakhtin and Benveniste, $V y g o t s k y$ conceives the relation between language and cognition in an enunciative perspective.

\section{Bibliografia}

Bakhtin, M. Marxismo e Filosofia da Linguagem. São Paulo: Hucitec, 1981. [Original de 1929]

Benveniste, É. Problèmes de Linguistique Générale vol. I. Paris: Gallimard, 1966.

Dascal, M. Pragmatics and Philosophy of Mind. Amsterdam: John Benjamins, 1983.

De Lemos, C.T.G. Aquisição da linguagem: um lugar de reflexão sobre processos de subjetivação e objetivação. "Conferência proferida por ocasião do I Simpósio de Neuropsicologia, FCM/Unicamp" 1990.

Franchi, C. Reflexões sobre a hipótese da modularidade da mente. ABRALIN 8:63-76, 1986.

. "Linguagem - atividade constitutiva". Almanaque 5:9-27, 1977.

Humboldt, W. Linguistic Variability \& Intellectual Development. Philadelphia: University of Pennsylvania Press, 1972. [Original em 1836]

Lahud, M. "Da família jansenista". Cadernos de Estudos Lingüísticos 22:173-181, 1992.

A propósito da noção de dêixis. São Paulo: Ática, 1979 [Original de 1973]

Meschonnic, H. La Pensée dans la Langue: Humboldt et après. Saint Denis: PUF, 1995.

Morato, E.M. Linguagem e Cognição: as reflexões de L. S. Vigotski sobre a ação reguladora da linguagem. São Paulo: Plexus, 1996.

Normand, C. La quadrature du sens. Paris: PUF, 1990.

Pêcheux, M. O discurso: estrutura ou acontecimento. Campinas: Pontes, 1990. [Original de 1983].

Possenti, S. Um cérebro para a linguagem. ABRALIN 13:75-84, 1992. 
Vico, G. La scienza nuova. Laterza, Bari: Fausto Nicolini, 1978. [Original de 1744]

Vigotski, L.S. "Psicologia Concreta do homem" Tradução de Enid Abreu Dobránsky do texto "Concrete human psychology", publicado pela Soviet Psychology, v.17 (2), 1986, 1995. Mimeo.

. Thinking And Speech - The Collected Works Of L.S. Vigotski (Vol I: Problems Of General Psychology. (Rieber, R. \& Carton, A., eds.). New York: Plenun Press, 1987. [Original de 1934]

A formação social da Mente. São Paulo: Martins Fontes. [Tradução de "Mind in Society" (1978), The President and Fellows of Harvard College], 1984. [Original de 1930]

Wittgenstein, L. Investigações Filosóficas. São Paulo: Abril Cultural, 1975. [Original de 1956] 